\title{
Seed security response during COVID-19: building on evidence and orienting to the future
}

\author{
Louise Sperling ${ }^{1}$
}

Received: 17 May 2020 / Accepted: 30 June 2020 / Published online: 26 July 2020

(C) International Society for Plant Pathology and Springer Nature B.V. 2020

\begin{abstract}
In response to COVID-19, seed security interventions are being planned to help bolster fragile livelihoods. After 25 years of research during emergencies, there are many lessons to build on, including that seed systems, especially informal markets, prove fairly resilient and often function even in high stress contexts. As a wise first step, given the possible volatility in supply, farmers' seed saving should be supported actively and at scale. Rigorous remote assessments will have to become the new norm for gauging seed security, with reviews recognizing that different crops might be affected in different ways by specific seed channel stress or breakdown. Well-known short-term seed security responses, for example, Direct Seed Distribution, will need to be tailored to the new COVID-19 reality, particularly in terms of altering logistics. More fundamentally, three new factors might herald a transformation in response: 1) Choice for farmers has to be the operative principle (especially as markets may fluctuate quickly); 2) Remote two-way 'state of the art' communication has to be built rapidly; and 3) Seed quality options might need to be liberalized, especially given the scale of possible seed security intervention. Covid-19 effects will likely linger several years or potentially six to nine seasons (depending on agricultural calendar). Now might be the time to move from stop-gap responses (and repetitive ones) to more sustainable and powerful market-led support, with particular emphasis on responses that leverage and strengthen the informal sector markets.
\end{abstract}

Keywords COVID-19 $\cdot$ Seed security $\cdot$ Smallholders $\cdot$ Africa $\cdot$ Humanitarian aid $\cdot$ Market-led support

COVID-19 is bringing new challenges, including to smallholder farmers, seed systems, and seed security response. As the first wave of humanitarian assistance unfolds, centring on life-saving interventions such as support to health centres, a second wave is already in the planning, to bolster fragile rural livelihoods. Seed security interventions are included in that second push, with the logic being that-if farmers have enough seed and of the right type - they can plant, harvest, and largely control essential food security themselves.

Policy makers and researchers have been monitoring seed security humanitarian response for several decades now, but most intensively since the Rwandan genocide/civil war in 1994, so for some 25 years. This opinion piece shares a few of the lessons learned, focusing mainly on Africa, where the lion's share of humanitarian seed assistance has been implemented.

Louise Sperling

sperling@seedsystem.org

1 SeedSystem, Sherman, CT, USA
COVID-19 response, linked to seed security interventions, first and foremost, needs to be evidence-based. Intervening in seed systems is serious business. Even short-term interventions may have important effects over many seasons or years: e.g. seed can be replanted. Also, while seed interventions have a benign image, bad seed aid can do very significant harm and increase farmers' vulnerability. In the short-term, late or unadapted seed is directly harmful as it wastes farmers' land and labour and takes space on plots that might have been otherwise productive. In the longer-term, aid, especially repeated aid, generates farmer dependency, undermines formal and private sector seed enterprise, and compromises local markets. Repeated seed-related aid has become the norm, not the exception, in African disaster hotspots, chronically-stressed areas and fragile state regions. For example, Burundi has received some form of seed aid for over 38 growing seasons, Kenya, on and off since 1992, and Ethiopia over 42 years. COVID-19 may be new, but the virus also adds an additional layer of stress onto existing ones: locusts, drought, civil unrest, displacement or a combination of these. The lessons from seed security-related experience should also be additive: there 
is a good deal of background insight on which to build effective COVID-19 (and other stress) response. Several essential points are emphasized below.

I. Build on what we already know about seed systems in stress

Smallholder farmers (the focus of this guidance) commonly seek their seed from multiple sources.

Some might come from what they have saved; some from social networks of friends, relatives and neighbours; some from formal sources such as agro-dealers, particularly for crops such as hybrid maize. However, one particular source is central for seed: local markets. Local markets are accessed especially for the poor, those in stress situations, and even the displaced (Sperling and McGuire 2010). ${ }^{1}$

Evidence from the largest seed system data set in the world (published in FOSE, McGuire and Sperling 2016) shows the relative importance of these channels for obtaining seed. Across crops, the biggest channels are local markets: $51 \%$ of seed sown; farmers' own seed stocks come next: $30 \%$; and social networks account for $8.6 \%$, with all of these being informal seed channels. The smaller channels, in terms of $\mathrm{kg}$ of seed sown, are: agro-dealers/seed companies: $2.4 \%$ of farmer seed; and community-based multiplier groups, providing, $0.5 \%$ of seed, with both these latter two conduits often supported by development initiatives. The rest of farmers' seed comes from government and non-governmental/ United Nations aid, representing 7\% from the two sources combined.

Data from some really high stress scenarios gives pithy insight into the resilience of these varied channels. In the first season just months after the Rwanda genocide/ civil war-with 800,000 people killed and 2,000,000 on the move- over 30 agencies poured seed aid into this tiny country. Evaluations showed that what bean farmers sowed came largely from their own stocks and local markets $(45 \%$ and $26 \%$ of bean seed respectively) with another quarter accessed from relief. In the second major post- war season, abundant aid continuing, farmers accessed over $92 \%$ of their bean seed from their own informal channels (40\% saved and 52\% bought at local markets) (Sperling 1997). The Haiti 2010 earthquake offers another example. The season immediately post- earthquake, only about $4 \%$ of the seed farmers sowed, across crops, came from aid (even with relief so abundant that the Haitian capital became a traffic jam of assistance). Despite infrastructure disruption in the southeast and massive exodus to the countryside, local markets particularly provided seed $(74.2 \%$ of that

\footnotetext{
1 'Potential seed' refers to grain sourced from local market that can be used for planting and which is often expressly purchased for seed. Such material is perceived to be adapted and with acceptable quality — as judged by the buyer. Such seed is also seen by traders (the suppliers) as a specific revenue stream and it may be actively managed as 'potential seed' as distinct from routine grain stocks.
}

sown) topped off by what farmers had saved themselves (17.8\% of seed) (SSSA report, Haiti). While dire constraints are often assumed -market breakdown, or farmers' eating their seed, or social networks collapsing- evidence from a range of disasters has yet to confirm these declines as either frequent or of a degree that would require urgent action.

There are already strong assumptions suggesting that several seed supply sources will be compromised by the COVID19 crisis: the local markets and social networks (informal channels that supply a range of crops) and agro-dealer/ formal sources (which mainly supply hybrid maize and sometimes vegetable seed). The assumptions for breakdown are multiple: farmers themselves are constrained to move and to gather in groups; markets days are being held less frequently or stopped all together; and supplies from both the informal and formal seed sectors may experience bottlenecks in the distribution channels (such as access to transport or business support services).

Given these possible threats, it makes sense to do several actions quickly and as priority.

a. Help farmers save the seed they have. Saved seed is already in farmers' fields or stocks, is likely adapted, and is of no cost. Support actions might include: massive information campaigns to save seed (phone, radio, SMS). Remote advice on better seed selection; and remote technical support on possible storage options (earthen jugs, plastic bottles, hermetic storage bags). Helping farmers to save seed proved to be among the more effective seed-related actions implemented during the Ebola period in Sierra Leone (Catholic Relief Services, Seedsystem and University of East Anglia/Dev 2014), a crisis with important similarities to COVID-19 (widespread disease contagion and limiting of movements).

b. Do rigorous remote market assessments, especially of the informal markets. Several initial guides already exist to help with this (SeedSystem 2020, UN Global Food Security Cluster 2020).

c. Apply known insight to assess differential seed channel functioning. Even if seed channels are disrupted, it is unlikely that seed channel failure or constraints will affect all crops equally. If formal seed channels are curtailed, (where much of the current aid support is now being harnessed), supplies of maize seed might be mostly affected. If there are constraints in local market functioning, legume seed could potentially be at risk. Should social distancing actually be practiced in the remote countryside, planting material of the vegetatively-propagated crops (VPCs) could potentially be hardest hit (see Fig. 1).

II. Tailor well-tried implementation approaches to a COVID-19 new reality 
Fig. 1 Smallholder farmers' seed sources for key crops (kg-basis): SSSA data set 2016. (modified from McGuire and Sperling 2016, Table 3).

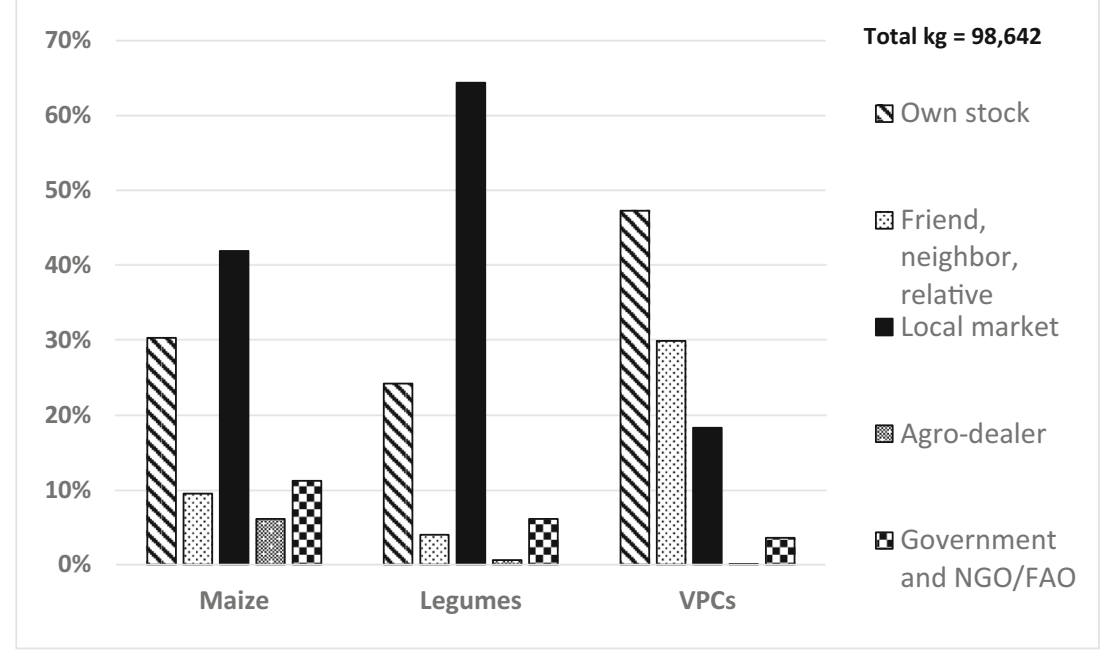

Assuming that a rigorous assessment has taken place and that some sort of intervention is needed, the three types of more practiced seed-linked responses will have to be somewhat reshaped to unfold in the new COVID-19 reality.

Direct Seed Distribution (DSD) has been the most common response for decades and is currently the preferred option for these COVID-19 times. DSD involves procurement of quality seed, usually from outside the agro-ecological region, for subsequent free delivery to farmers. Key questions posed during these virus times: can adapted crops and varieties be procured, especially as aid might be at scale? Can the quality of seed be verified given that formal seed inspection services are closed or minimally operating? Can DSDs be organized in time for planting, recognizing that even under 'normal' conditions DSD is often late and now only skeletal staff will be working?

Seed Fairs and Vouchers Fairs (SVF) - are the second most common seed-related response type. Vouchers or cash are provided to farmers to allow them to access seed themselves. This usually happens in specially organized fairs where vendors put different kinds of crops and seed on offer. The question posed in the presence of COVID-19 is whether it makes sense at all to encourage actively congregations of people - sellers and buyers - in a limited space for many hours at a time. Aid workers have suggested staggering days of the fair, and/or staggering times of beneficiary participation. The SVF approach might particularly be scrutinized for its potential of introducing harm (e.g. lots of social proximity with uneven mitigating measures).

Cash and Voucher Assistance- (CVA) is a well-known approach but, to date, has rarely been used linked to seed security work per se (see Keane et al. 2020). Cash or vouchers are provided, either physically or via remote transfer, so as to give the buyer (here farmer) purchasing power. With cash, farmers can buy whatever they want (seed or not seed;) from venues of their choice. Certainly, if this approach has not previously used by an aid organization, it might best not be tested during this first season of stress. Having sufficient seed supply will be the pivotal factor, including a diverse supply and at multiple outlets of sale.

Interestingly, the initial discussions on seed-related response and COVID-19 have focused on logistics: how to modify what aid organizations routinely do. However, three new factors suggest that aid response during COVID has to be about more than tinkering at the edges. It some cases, it will imply real transformation of practice.

\#1. Choice for farmers has to be the operative principle. Farmers will need to be able strategize in fluctuating conditions: which seed markets are functioning? can their products/produce sell? Farmers can pivot faster than aid organizations and need the freedom to do so.

\#2. Remote two-way communication has to be built into a new 'state of the art'. Skeletal humanitarian staff is already the norm and information coming back from farmers and traders has to be just as sharp as information going out. (This could be a silver lining as feedback evaluations on seed aid effectiveness are routinely few and far between.) \#3. Seed quality options might need to be liberalized, especially given the scale of possible seed security intervention. The requirement for certified seed often translates to few crops and varieties being considered in response and heavy transaction costs moving supplies across large distances from region $\mathrm{X}$ to $\mathrm{Y}$. Flexibility in quality requirements and decentralization of the screening process (even to local experts) could be positive outcome in the midst of this unfolding chaos.

A cautionary warning on response. This COVID-19 era, given it widespread presence and its projected timing to linger over years, could result in farmers being flooded with free 
seed the coming season, the season after and the season after that. COVID is here for the longer term. Hopefully repetitive aid will not follow the same course.

III. Think forward and expand response toward market-led support, especially to informal markets

Finally, it may be the widespread threat of COVID-19, over space and over time, that could spur seed security response to make the leaps urgently needed - towards sustainable approaches that catalyze supply in high stress areas. There is near nil humanitarian assistance focusing on bolstering the critical market-led channels from which farmers routinely get seed. A recent review (Walsh and Sperling 2020) documented only a few examples of market-led support in seedrelated aid, and those identified centred uniquely on formal channels and mostly supported advance seed multiplication. Not a single case was identified of informal market -led support, even though extensive evidence shows that such markets are the crux of smallholder farmer seed security.

Informal market-led support is not hard to conceptualize and evidenced-based field trials might pave the way for thinking about how to leverage these resources (Sperling and Mcguire 2010). An Informal seed trader already manages large scale seed collection (even 1500 MT per year) (Birachi et al. 2020), and can deliver a range of seed to the kinds of remote and stressed regions that will need to be increasingly served.

How might informal seed traders strategically be supported? A sample of practical actions are suggested below. ${ }^{2}$ All have been tested in diverse venues and are poised to be brought to scale.

Possible support to informal seed traders:

To enhance seed availability:

- Capital advances to traders/loans - to seek out supplies in anticipation of stress;

- Advocacy for relaxed quality restrictions- allowing for more supplies;

\section{To enhance seed access}

- Transport vouchers to traders (to move supplies to remote areas) (screened seed;.

- Permitting traders to sell small packs of certified seed- (so as to move new varieties);

To enhance seed quality

\footnotetext{
${ }^{2}$ Frameworks for a possible market-led support have been developed elsewhere and include distinct support actions toward the formal and informal seed sectors (e.g. Walsh and Sperling 2020).
}

- Working with traders to improve seed storage facilities, - even with local varieties;

- Working with traders to distinguish among varieties (even non-released) — and to keep variety stocks separate.

With the challenges of COVID-19, now might is the prime time to foster seed system resilience from the inside and strengthen to a new level the ongoing markets that serve smallholders. COVID-19 will have effects over an extended period, with initial estimates up to three years or nine seasons (given a 3-season agricultural calendar). We might strive to lessen and eventually phase out the stop-gap types of seed assistance and halt their repeated implementation. This might be the prime time to learn and test and sharpen our approaches to bolstering especially the market channels that prove most resilient and most important for farmers' seed security. Saving seed could be strategic in this time of COVID-19. Supporting Informal markets could be even more so. This period of COVID and seed could potentially become one marked by real thinking and re-orientation, a time when seed security assistance learns how to support ongoing delivery systems and ones that might continue to operate even in the more remote and fragile of states.

Acknowledgements Special thanks to Patrick Gallagher who helped with last-minute data analysis.

A recent webinar gives additional insight into COVID-19 and seed security response. https://www.youtube.com/watch?v=OFXke6aqwV0

\section{Compliance with ethical standards}

Conflict of interest The author declares that she has no conflict of interest.

\section{References}

Birachi, E. A., Sperling, L., Kadege, E., Mdachi, M., Upendo, T., Radegunda, K., Mutua, M., Mbiu, J., Raya, N., Ndunguru, A., William, M., Kabungo, C., Mcharo, D., Shida, N., Kilango, M., Magelanga, A., Maganga, R., Kalemera, S., Katungi, E., Mukankusi, C., Malle, S., Dey, B., Templer, N., Rubyogo, J. C., Onyango, P., \& Buruchara, R. (2020). An Analysis of the Yellow Bean Corridor: a status report of Tanzania. Arusha: CIAT.

Catholic Relief Services, Seedsystem and University if East Anglia/Dev. (2014). Sierra Leone, Rapid Seed System Security Assessment. Baltimore: Catholic Relief Services.

Keane, J., Brick, D. and Sperling, L. 2020. Cash transfers and humanitarian seed security response: https://seedsystem.org/wpcontent/ uploads/2020/04/S34D-Study-on-cash-transfers-for-seed-security final.pdf. Baltimore MD, S34D project.

McGuire, S. J., \& Sperling, L. (2016). Seed systems smallholder farmers use. Food Security, 8, 179-195.

SeedSystem. 2020. Seed security lessons + COVID-19. https:// seedsystem.org/wp-content/uploads/2020/04/COVID-19-and-SeedSecurity-April-13-2020.pdf

Sperling, L. (1997). The effects of the Rwandan war on crop production and varietal diversity: A comparison of two crops. In L. Sperling 
(Ed.), War and Crop Diversity, AGREN network paper no.75 (pp. 19-30). London: Overseas Development Institute.

Sperling, L., \& McGuire, S. J. (2010). Understanding and strengthening informal seed markets. Experimental Agriculture, 46, 119-136.

United Nations Global Food Security Cluster. 2020. Guidance for Emergency Seed Interventions during the COVID-19 pandemic. https://fscluster.org/covid19_twg/document/guidance-emergencyseed-interventions

Walsh and Sperling. (2020). Review of practice and possibilities for market-led interventions in Emergency Seed Security Response. Baltimore: S34D Project.

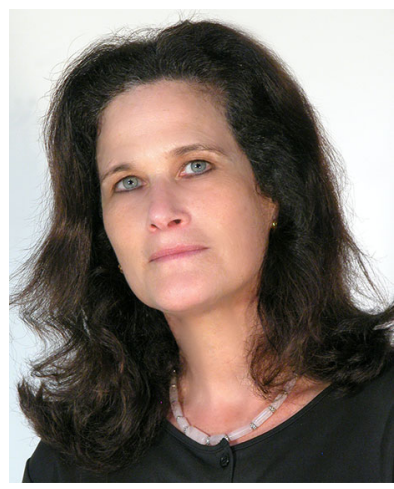

Louise Sperling is Coordinator of SeedSystem.org. She has managed and technically backstopped agricultural programs in over 30 countries in Africa, Asia and Latin America. In terms of seed systems, per se, Sperling's work encompasses normal smallholder farmer systems as well as high stress ones: for example, she led assessment missions after the 1994 Rwandan genocide, postearthquake in Haiti, and preReferendum South Sudan. Sperling has co/-authored over 100 articles, inter alia: Seed systems farmers use (Food Security 2016);
Making seed systems more resilient (Global Environmental Change 2013, Understanding and strengthening informal seed markets (Experimental Agriculture 2010), and Moving towards more effective seed aid (Journal of Development Studies 2008). The website SeedSystem.org shares practical and policy advice for those supporting smallholder farmer seed systems in crisis, chronic stress and developmental periods. 